Article

\title{
Developing a Fast Ultra-High-Performance Liquid Chromatography-Tandem Mass Spectrometry Method for High-Throughput Surface Contamination Monitoring of 26 Antineoplastic Drugs
}

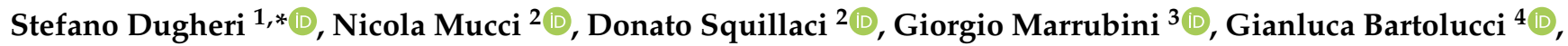 \\ Camillo Melzi ${ }^{5}$, Elisabetta Bucaletti ${ }^{2}$, Giovanni Cappelli ${ }^{2}$, Lucia Trevisani ${ }^{2}$ and Giulio Arcangeli ${ }^{2}$ \\ 1 Industrial Hygiene and Toxicology Laboratory, Occupational Medicine Unit, Careggi University Hospital, \\ 50134 Florence, Italy \\ 2 Department of Experimental and Clinical Medicine, University of Florence, 50134 Florence, Italy; \\ nicola.mucci@unifi.it (N.M.); donato.squillaci@unifi.it (D.S.); elisabetta.bucaletti@unifi.it (E.B.); \\ giovanni.cappelli@unifi.it (G.C.); lucia.trevisani@unifi.it (L.T.); giulio.arcangeli@unifi.it (G.A.) \\ 3 Department of Drug Sciences, University of Pavia, Via Taramelli 12, 27100 Pavia, Italy; \\ giorgio.marrubini@unipv.it \\ check for \\ updates \\ Citation: Dugheri, S.; Mucci, N.; \\ 4 Department of Neurosciences, Psychology, Drug Research and Child Health, University of Florence, \\ 50019 Sesto Fiorentino, Italy; gianluca.bartolucci@unifi.it \\ 5 Metanalisi, Corso di Porta Venezia 40, 20121 Milano, Italy; camillomelzi@gmail.com \\ * Correspondence: stefano.dugheri@unifi.it
} Squillaci, D.; Marrubini, G.;

Bartolucci, G.; Melzi, C.; Bucaletti, E.; Cappelli, G.; Trevisani, L.; Arcangeli, G. Developing a Fast Ultra-High-Performance Liquid Chromatography-Tandem Mass Spectrometry Method for High-Throughput Surface Contamination Monitoring of 26 Antineoplastic Drugs. Separations 2021, 8, 150. https://doi.org/ 10.3390 /separations 8090150

Academic Editor: Achille Cappiello

Received: 3 August 2021

Accepted: 7 September 2021

Published: 10 September 2021

Publisher's Note: MDPI stays neutral with regard to jurisdictional claims in published maps and institutional affiliations.

Copyright: (c) 2021 by the authors. Licensee MDPI, Basel, Switzerland. This article is an open access article distributed under the terms and conditions of the Creative Commons Attribution (CC BY) license (https:// creativecommons.org/licenses/by/ $4.0 /)$.
Abstract: Growing attention on carcinogenicity and mutagenicity of antineoplastic drugs (ADs) from the International Agencies has led to the present strict safe handling and administration regulations. Accordingly, one of the most common ways to assess occupational exposure to these substances is to identify and quantify possible surface contamination inside hospital preparation and administration units. Thus, it is essential to develop a fast and high-throughput monitoring method capable of identifying a significant number of ADs. The present study reports developing a UHPLC-MS/MS analysis to screen 26 ADs surface contamination through wipe test sampling. A Cortecs UPLC T3 $50 \times 2.1 \mathrm{~mm}(1.6 \mu \mathrm{m})$ column was selected to perform the analysis, using the evaluations of previous studies and the Product Quality Research Institute (PQRI) database. The design of experiments (DoE) methodological approach was used to optimize the chromatographic conditions concerning the best separation between all ADs. The limits of quantification for the analytes were between the $\mathrm{pg} / \mathrm{mL}$ and $\mathrm{ng} / \mathrm{mL}$ orders, and the turnaround time was limited to about $15 \mathrm{~min}$. The obtained accuracy was mostly between $90 \%$ and $110 \%$ for all the analytes, while the precision was under $10 \%$ and a low matrix effect was observed for said analytes. Only vindesine and docetaxel presented lower performances.

Keywords: antineoplastic drugs; wipe test; ultra-high-performance liquid chromatography; tandem mass spectrometry; design of experiments; PQRI

\section{Introduction}

In 2020, more than 19 million new cancer cases occurred worldwide, and if the growth rates remain constant, that number is expected to rise by $47 \%$ by 2040 [1].

The growing number of cases of this disease is associated with increased use of cytotoxic antineoplastic drugs (ADs), which require strictly controlled conditions to assure a safe administration to the patients, with the lowest possible risk for healthcare professionals [2].

Many chemotherapy drugs are mutagenic and carcinogenic. They are considered high-risk pharmaceutical formulations, both for the patients and healthcare professionals and their working environment. Thus far, the International Agency for Research on Cancer 
(IARC) has classified 43 active components of ADs into diverse carcinogenicity groups [3]. However, until today, in the European Union, chemotherapy drugs have no harmonized legally binding Classification, Labelling, and Packaging (CLP) regulation criteria, and there is no obligation to prepare Safety Data Sheets [4].

In 2016, the National Institute for Occupational Safety and Health (NIOSH) published an alert on ADs and other hazardous drugs that proposed safe handling practices for all healthcare workers [5].

In addition, in January 2019, the American Conference of Governmental Industrial Hygienists (ACGIH) firstly introduced a new category of the limit value referred to assess surface contamination, called the threshold limit value-surface level (TLV-SL). In February 2019, the European Parliament approved amendments to Directive 2004/37/CE on carcinogens and mutagens and their implications for the healthcare sector (the Carcinogens and Mutagens Directive) [6]. Recommendation No. 11 from "Preventing occupational exposure to cytotoxic and other hazardous drugs. European Policy Recommendations" promotes the use of environmental monitoring procedures to detect how the drugs in question are released and spread, and thus to control and improve the effectiveness of protective measures and equipment [7]. Additionally, the European Biosafety Network has recently published a document recommending a value of $100 \mathrm{pg} / \mathrm{cm}^{2}$ for the surface threshold contamination of ADs [8].

Thanks to dedicated AD preparation units inside the hospital pharmacies and the growing care in creating accurate preparation guidelines [9,10], the healthcare personnel's risk of absorption of high quantities ADs has seen a significant decrease [11]. This lowering of detected urinary levels, along with the growing number of ADs chemistries, makes the creation of a unique method for exposition monitoring extremely complex and hardly sustainable, even considering the need to create different extraction methods for each class of ADs and consequently to have more runs for each sample [12-14]. For this reason, surface contamination monitoring is becoming the first choice for occupational AD risk assessments, usually performed through a wipe sampling test [15-21].

For a similar purpose, Guichard et al. [22] reported the use of a core-shell reverse phase C18 column, the Cortecs ${ }^{\circledR}$ UPLC T3 $(100 \times 2.1 \mathrm{~mm}, 1.6 \mu \mathrm{m})$, commercialized by Waters since $2017[23,24]$. Waters T3 bonding appears to be an accurate choice to retain a wide range of polarities such as those shown by the ADs due to its trifunctional C18 alkyl phase, which gives the polar analytes improved access to the silanol groups of the underlying base particle [25].

The present work aimed to develop a fast, high-throughput method of analysis to screen AD contamination on many wipe samples with reasonable turnaround time and high sensitivities. The novelty of this paper lies in the creation of a method able to analyze 26 ADs in less than $15 \mathrm{~min}$, with a single step of sample preparation. The study of the best operative conditions to achieve the goals said was based on the application of design of experiments (DoE) methodology of research, as recently reviewed [26]. The method presented in this report will allow occupational hygienists to check and identify personnels potentially dangerous behaviors and better understand the contamination patterns in the hospital environment. Ultra-high-performance liquid chromatography coupled with tandem mass spectrometry (UHPLC-MS/MS) allowed achieving a good chromatographic resolution with fast analysis times and low limits of quantification.

In this context, to obtain a clearer understanding of the alternatives to the Cortecs T3 column available on the market, the authors decided to use a column comparison database. Four central databases are available for this purpose. They are the ACD Labs Column Selection Database [27], the United States Pharmacopeial Convention (USP) database [28], the Impurities Working Group of the Product Quality Research Institute (PQRI) Drug Substance Technical Committee [29], and the Hoogmartens [30-33]. The PQRI database, which at the time being holds a broader number of column chemistries, has been chosen for the purposes of this study, being the only one including the previously mentioned Cortecs T3. 


\section{Materials and Methods}

\subsection{Chemicals}

Acetonitrile, water, and methanol ultra-high-performance liquid chromatography/mass spectrometer (ULC/MS) were from Biosolve Chimie SARL (Dieuze, France). Formic acid (99\%) LC/MS grade was from Carlo Erba reagents (Milan, Italy). Bendamustine hydrochloride hydrate $(\geq 98 \%)$, busulfan (analytical standard), cephalomannine ( $\geq 97 \%)$, cyclophosphamide monohydrate, dacarbazine, daunorubicin hydrochloride $(\geq 90 \%)$, docetaxel ( $\geq 97 \%)$, doxorubicin hydrochloride (98-102\%), epirubicin hydrochloride ( $\geq 90 \%)$, etoposide (98-105\%), fotemustine ( $\geq 98 \%$ ), idarubicin hydrochloride, iphosphamide ( $\geq 98 \%)$, irinotecan hydrochloride, melphalan, methotrexate hydrate $(\geq 98 \%)$, mitomycin $C$, paclitaxel $(\geq 95 \%)$, pemetrexed disodium heptahydrate $(\geq 98 \%)$, raltitrexed $(\geq 98 \%)$, tamoxifen $(\geq 99 \%)$, topotecan hydrochloride hydrate $(\geq 98 \%)$, vinblastine sulfate salt $(\geq 97 \%)$, vincristine sulfate salt (95-105\%), vindesine sulfate salt hydrate ( $\geq 95 \%)$, vinorelbine ditartrate salt hydrate $(\geq 98 \%)$, each HPLC grade and Ammonium formate ( $\geq 99.0 \%$ ) was MS grade, were all purchased from Merck KGaA (Darmstadt, Germany).

The drug products dacarbazine, daunorubicin, docetaxel, doxorubicin, epirubicin, etoposide, idarubicin, iphosphamide, irinotecan, melphalan, methotrexate, paclitaxel, topotecan, vinblastine, vincristine, and vinorelbine were purchased from Teva Pharmaceutical Industries Ltd. (Petah Tiqwa, Israel). Cyclophosphamide was obtained from Baxter (Deerfield, IL, USA). Bendamustine, mitomycin, and pemetrexed were from Accord Healthcare Inc. (Durham, NC, USA). Busulfan was from American Reagent Inc. (Shirley, NY, USA). Fotemustine was purchased from Les Laboratoire Servier (Suresnes, France). Raltitrexed was from Pfizer Italia S.r.l. (Milan, Italy). Vindesine was obtained from EG S.P.A (Milan, Italy).

The desorption solution (DS) consisted of a mixture of methanol:water 50:50 (v/v).

\subsection{Instruments}

The LC system consisted of a Shimadzu Nexera X2 equipped with a DGU-20A5R degasser unit, two LC-30AD pumps, SIL-30AC autosampler, CBM-20A system controller, SPD-M20A diode array detector, and CTO-20AC column oven. The tandem mass spectrometry system was a Shimadzu LCMS 8050 triple quadrupole equipped with an electrospray source (ESI). The software LabSolution ${ }^{\circledR}$ ver. 5.97 (Shimadzu Corp., Kyoto, Japan) performed instrument control and data acquisition.

Mobile phases' pH values were measured using a Hanna ${ }^{\circledR}$ instruments portable pHmeter mod. HI8424 (HANNA INSTRUMENTS Italia srl, Ronchi di Villafranca Padovana, PD, Italy), equipped with a pH electrode HI1230B and a temperature probe HI7662.

Climatic Cabinet Sartorius SCC400L (GEASS S.R.L., Torino, Italy) was used to weigh Internal Standard, chemical standards, and ammonium formate salt.

\subsection{Standard Solutions and Calibration Levels}

Stock solutions of cephalomannine, selected as internal standard (IS), and of all the 26 analytes were prepared at $1 \mathrm{mg} / \mathrm{mL}$ using DS mixture as the solvent and stored at $-20{ }^{\circ} \mathrm{C}$. The study of MS parameters was carried out using $2 \mu \mathrm{g} / \mathrm{mL}$ working solution of each analyte prepared in a DS mixture.

Each drug product was diluted with DS to obtain Pharmaceutical stock solutions at a $1 \mathrm{mg} / \mathrm{mL}$ concentration.

The ADs calibration mixture (MixADs solution) was prepared by adding $10 \mu \mathrm{L}$ of each Pharmaceutical stock solution-except for tamoxifen, which was added from the stock solution-and diluted to $10 \mathrm{~mL}$ with DS to obtain a $1 \mu \mathrm{g} / \mathrm{mL}$ concentration for all the analytes. The IS solution was obtained by diluting its stock solution with a DS mixture up to $1 \mu \mathrm{g} / \mathrm{mL}$.

A seven-level calibration curve was prepared by adding $10 \mu \mathrm{L}$ of IS solution, an appropriate volume of MixADs, and DS mixture to reach a final volume of $1 \mathrm{~mL}$. Following this procedure, the analyte concentrations in the calibration solutions were: $0,5,10,20,30$, 
40, $50 \mathrm{ng} / \mathrm{mL}$. Furthermore, three levels of internal quality control solutions (CQI) were prepared by diluting MixADs solution with DS mixture to obtain 6 (low level), 25 (medium level), and $45 \mathrm{ng} / \mathrm{mL}$ (high level); each CQI solution contained IS in a concentration of $10 \mathrm{ng} / \mathrm{mL}$.

The experimental design study for optimizing the chromatographic method was performed using the freshly prepared MixADs solution at $25 \mathrm{ng} / \mathrm{mL}$ concentration.

\subsection{Sample Preparation}

As reported in previous papers [18], a wipe consisted of a $5 \times 5 \mathrm{~cm}$ nonwoven fabric gauze wetted with $500 \mu \mathrm{L}$ of 50:50 water/methanol solution, used to swab areas contaminated by ADs in hospital drug preparation and administration units. Then, the analytes were desorbed from the wipe with $2 \mathrm{~mL}$ of the DS mixture added with $10 \mathrm{ng} / \mathrm{mL}$ of IS.

Two sets of six replicate samples were prepared to evaluate the matrix effect (ME) for each analyte [34]. Set1 was obtained by desorbing blank wipes with $2 \mathrm{~mL}$ of DS mixture, transferring $1.92 \mathrm{~mL}$ of this solution in a vial, and adding $80 \mu \mathrm{L}$ of MixADs, while Set2 was prepared by diluting $80 \mu \mathrm{L}$ of MixADs solution with $1.92 \mathrm{~mL}$ of DS mixture.

Each solution was filtered through a $0.2 \mu \mathrm{m}$ GHP Acrodisc ${ }^{\circledR}$ syringe filter (Pall Corporation, New York, NY, USA) before analysis.

\subsection{PQRI}

The columns potentially equivalent to the selected one were checked on the PQRI database. This database is accessible through the Internet and allows finding columns with a similar selectivity to the one selected by the user.

Following the database instructions [35], the Waters Cortecs T3 was selected as a reference column, along with a hypothetical mild acidic mobile phase $(\mathrm{pH}=4)$ and the presence, between the analytes, of acids and bases due to the variety of chemical classes among the ADs. The columns displayed by the website as potential substitutes of the Cortecs T3 column were given a "value of correspondence", defined as "F." The F value is inversely proportional to the similarity between the proposed column and the reference one. Therefore, by its definition, $\mathrm{F}=0$ means perfect equivalence.

\subsection{Experimental Design}

The development of the gross chromatographic method was rapid. After several preliminary chromatographic runs, the column temperature, flow rate, and percent of methanol in the mobile phase provided satisfactory results and were thus not further worthy of investigation.

However, the application of a minimal full factorial $2^{2}$ experimental design plus three validation points helped to evaluate the multivariate set of responses represented by peak area, retention time $\left(t_{R}\right)$, signal-to-noise ratio measured between the peak height and the baseline noise near the peak, peak width at half-height $\left(\mathrm{w}_{1 / 2}\right)$, tailing factor, and absolute noise measured in a specific region of the chromatogram.

The factors studied were the concentration of ammonium formate (from 1 to $5 \mathrm{mM}$ ), and the percent of formic acid (from $0.01 \%$ to $0.1 \%, v / v$ ) in the mobile phase, as shown in Table 1. The authors selected the validation experiment V1 conditions in the median points of the interval for formic acid and ammonium formate concentration chosen for building. Additionally, the authors arbitrarily chose two more points for testing the model's predictive reliability, namely experiments V2 and V3. Experiment V2 corresponds to operating conditions considered optimal; experiment V3 instead is a random point selected within the model's domain. Experiments V1, V2, and V3 allowed assessing the concordance between the model predictions and the experimental observations. 
Table 1. Experimental plan and experimental matrix of the design.

\begin{tabular}{ccccc}
\hline & \multicolumn{2}{c}{ Experimental Plan } & \multicolumn{2}{c}{ Experimental Matrix } \\
\hline Exp\# & {$\left[\mathrm{HCOONH}_{4}\right](\mathrm{mM})$} & $\mathrm{HCOOH}(\%, v / v)$ & AMF & FA \\
\hline 1 & 5 & 0.1 & 1 & 1 \\
2 & 1 & 0.1 & -1 & 1 \\
3 & 5 & 0.01 & 1 & -1 \\
4 & 1 & 0.01 & -1 & -1 \\
\hline $5(\mathrm{~V} 1)$ & 3 & 0.055 & 0.5 & 0 \\
$6(\mathrm{~V} 2)$ & 4 & 0.021 & -0.5 & 0.75 \\
$7(\mathrm{~V} 3)$ & 2 & 0.088 & 0.75 \\
\hline
\end{tabular}

LEGEND: Exp\#, experiment number. Experiments 1-4 provided the results for model computation, whereas experiments 5-7 served to validate the models. V1, V2, and V3 stand for validation experiments. AMF and FA are notations indicating the coded values of the actual factors represented by ammonium formate and formic acid, respectively.

The data were collected using Microsoft Excel and processed using RStudio Version 1.2.1335 @2009-2019 RStudio, Inc., as GUI for R version 3.6.1 (2019-07-05) "Action of the Toes", (C2019 (RStudio PBC, Boston, MA, USA). The R Foundation for Statistical Computing.

\subsection{Chromatography and Instrument Parameters}

Gradient elution, indicated in Table 2, was applied to the Waters Cortecs ${ }^{\circledR}$ UPLC T3, $50 \times 2.1 \mathrm{~mm}, 1.6 \mu \mathrm{m}$, column, at a constant flow rate of $0.55 \mathrm{~mL} / \mathrm{min}$. The total analysis time was of $13.2 \mathrm{~min}$. The mobile phases were optimized by testing different levels of ammonium formate and formic acid concentrations, as shown in Table 1. Mobile phase A consisted of water with a concentration of ammonium formate varying from 1 to $5 \mathrm{mM}$ and of formic acid from $0.01 \%$ to $0.1 \%(v / v)$; mobile phase B consisted in acetonitrile:methanol 90:10 $(v / v)$ mixture with the identical formic acid additions of the corresponding mobile phase A. Each solution was sonicated for $15 \mathrm{~min}$ to clear it from dissolved gasses and avoid gas bubbles in LC pumps.

Table 2. Elution gradient.

\begin{tabular}{cc}
\hline Time (min) & Conc B (\%) \\
\hline 0.00 & 10 \\
0.70 & 10 \\
7.70 & 85 \\
7.71 & 90 \\
9.20 & 90 \\
9.21 & 10 \\
13.20 & 10 \\
\hline
\end{tabular}

The column thermostat was maintained at a fixed temperature of $30^{\circ} \mathrm{C}$ for each run. The settings of the ESI source, operating in positive ion mode, were the following: interface voltage $-4 \mathrm{kV}$, nebulizing gas flow $-3 \mathrm{~L} / \mathrm{min}$, heating gas flow-10 L/min, interface temperature $-300{ }^{\circ} \mathrm{C}$, desolvation temperature $-526^{\circ} \mathrm{C}$, desolvation line temperature$250{ }^{\circ} \mathrm{C}$, heat block temperature $-400{ }^{\circ} \mathrm{C}$ and drying gas flow $-10 \mathrm{~L} / \mathrm{min}$. The injection volume was $5 \mu \mathrm{L}$ for each run.

\subsection{MS/MS Experiments}

Positive scan spectra of the working solutions described in Section 2.3 were acquired in a range from 150 to $900 \mathrm{~m} / \mathrm{z}$ with a scan time of $0.500 \mathrm{~s}$.

The analytes product ion scan (PIS) spectra were acquired to study the fragmentation of each molecule by selecting the most representative ion registered in their MS spectrum. Each working solution was analyzed via flow injection analysis by six injections with 
increasing collision energies from 5 to $55 \mathrm{~V}$. Collision breakdown curves were built using the relative intensities values of each signal present in the MS/MS spectra.

The UHPLC-MS/MS analysis was performed in positive ion mode by multiple reaction monitoring (MRM) using a dwell time of $10 \mathrm{msec}$. The precursor ion species and $\mathrm{m} / \mathrm{z}$, product ions, and collision energies are reported in Table 3.

Table 3. Optimized parameters set in MRM mode, showing the quantifier and qualifier ions for each analyte with the corresponding collision energy (CE) utilized.

\begin{tabular}{ccccc}
\hline Compound & $\begin{array}{c}\text { Precursor Ion } \\
\text { Species }\end{array}$ & $\begin{array}{c}\text { Precursor Ion } \\
(\mathbf{m} / \mathbf{z})\end{array}$ & $\begin{array}{c}\text { Quantifier Ion } \\
(\mathbf{m} / \mathbf{z})[\mathbf{C E} \mathbf{( V )}]\end{array}$ & $\begin{array}{c}\text { Qualifier Ion } \\
(\mathbf{m} / \mathbf{z})[\mathbf{C E}(\mathbf{V})]\end{array}$ \\
\hline Dacarbazine & {$[\mathrm{M}+\mathrm{H}]^{+}$} & 183.05 & $166.0[-12]$ & $122.9[-18]$ \\
Methotrexate & {$[\mathrm{M}+\mathrm{H}]^{+}$} & 455.25 & $308.1[-20]$ & $175.1[-36]$ \\
Busulfan & {$\left[\mathrm{M}+\mathrm{NH}_{4}{ }^{+}\right.$} & 264.25 & $151.1[-11]$ & $55.1[-18]$ \\
Mitomycin C & {$[\mathrm{M}+\mathrm{H}]^{+}$} & 335.20 & $241.95[-15]$ & $131.2[-47]$ \\
Topotecan & {$[\mathrm{M}+\mathrm{H}]^{+}$} & 422.20 & $377.0[-23]$ & $46.0[-18]$ \\
Pemetrexed & {$[\mathrm{M}+\mathrm{H}]^{+}$} & 428.20 & $281.1[-20]$ & $163.0[-34]$ \\
Vindesine & {$[\mathrm{M}+2 \mathrm{H}]^{2+}$} & 377.60 & $355.2[-19]$ & $271.7[-25]$ \\
Raltitrexed & {$[\mathrm{M}+\mathrm{H}]^{+}$} & 459.05 & $312.0[-18]$ & $173.0[-35]$ \\
Ifosfamide & {$[\mathrm{M}+\mathrm{H}]^{+}$} & 261.05 & $153.9[-22]$ & $91.9[-23]$ \\
Irinotecan & {$[\mathrm{M}+\mathrm{H}]^{+}$} & 587.30 & $502.0[-33]$ & $124.0[-38]$ \\
Cyclophosphamide & {$[\mathrm{M}+\mathrm{H}]^{+}$} & 260.95 & $139.95[-22]$ & $105.9[-21]$ \\
Vincristine & {$[\mathrm{M}+2 \mathrm{H}]^{2+}$} & 413.10 & $382.9[-19]$ & $362.0[-21]$ \\
Vinblastine & {$[\mathrm{M}+2 \mathrm{H}]^{2+}$} & 406.10 & $346.1[-22]$ & $271.6[-27]$ \\
Melphalan & {$[\mathrm{M}+\mathrm{H}]^{+}$} & 305.10 & $288.0[-13]$ & $246.0[-23]$ \\
Doxorubicin & {$[\mathrm{M}+\mathrm{H}]^{+}$} & 544.20 & $397.1[-14]$ & $361.1[-29]$ \\
Epirubicin & {$[\mathrm{M}+\mathrm{H}]^{+}$} & 544.20 & $397.0[-15]$ & $360.9[-29]$ \\
Etoposide & {$[\mathrm{M}+\mathrm{NH}]^{+}$} & 606.25 & $229.0[-20]$ & $185.0[-44]$ \\
Vinorelbine & {$[\mathrm{M}+2 \mathrm{H}]^{2+}$} & 390.10 & $357.2[-27]$ & $122.0[-15]$ \\
Fotemustine & {$[\mathrm{M}+\mathrm{H}]^{+}$} & 316.10 & $210.1[-11]$ & $152.1[-24]$ \\
Daunorubicin & {$[\mathrm{M}+\mathrm{H}]^{+}$} & 528.10 & $381.1[-12]$ & $321.1[-28]$ \\
Idarubicin & {$[\mathrm{M}+\mathrm{H}]^{+}$} & 498.10 & $350.9[-11]$ & $291.1[-34]$ \\
Tamoxifen & {$[\mathrm{M}+\mathrm{H}]^{+}$} & 372.15 & $178.0[-50]$ & $72.1[-23]$ \\
Docetaxel & {$[\mathrm{M}+\mathrm{Na}]^{+}$} & 830.35 & $549.0[-27]$ & $304.05[-24]$ \\
Paclitaxel & {$[\mathrm{M}+\mathrm{H}]^{+}$} & 854.40 & $104.9[-53]$ & $569.2[-12]$ \\
Thiotepa & {$[\mathrm{M}+\mathrm{H}]^{+}$} & 190.10 & $147.1[-14]$ & $104.0[-22]$ \\
Bendamustine & {$[\mathrm{M}+\mathrm{H}]^{+}$} & 358.15 & $340.05[-25]$ & $228.1[-39]$ \\
IS & {$[\mathrm{M}+\mathrm{H}]^{+}$} & 832.45 & $569.2[-15]$ & $264.1[-19]$ \\
\hline
\end{tabular}

\subsection{Performance Evaluation of LC-MS/MS Methods}

To evaluate the interday repeatability of the optimized method, three sets of the calibration and CQI solutions were freshly prepared and analyzed every day for six days. In contrast, for the intraday repeatability, six sets were prepared and analyzed in a single day. Calibration curves were obtained by plotting the peak area ratios (PAR) between the analyte and IS quantitation ions versus the nominal concentration of the calibration solution. Each run was performed using the mobile phase conditions expressed in paragraph 3.2. A linear regression analysis was applied to obtain the best fitting function between the calibration points. Limits of detection and quantitation (LOD and LOQ) were calculated according to ICH guidelines using the approach based on the standard deviation of blanks and slope of the regression [36].

The method precision was evaluated through the relative standard deviation (RSD\%) of the replicate analysis of low, medium, and high levels of CQI. The accuracy was determined through the ratio between the determined and added amounts expressed as a percentage. 
The matrix effect was calculated for each analyte by comparing the mean results of Set1 and Set2, formerly described according to the following formula:

$$
\operatorname{ME}(\%)=\frac{\text { Set } 1}{\text { Set2 }} \times 100
$$

The performance evaluation was carried out using the MS/MS parameters reported in Table 1 and the mobile phase composition is reported in Section 3.2.

\section{Results}

\subsection{PQRI Comparison}

Using $\mathrm{F}=3$ as a threshold value [37] and considering only the columns with $\mathrm{F}<3$, only one column reached the equivalency level required, namely the Develosil C30-UG-5 (Nomura Chemical Co., Ltd., Tokyo, Japan), which presented a value $\mathrm{F}=1.33$. However, the stationary phase chemistry was not available in a particle size smaller than $3 \mu \mathrm{m}$ [38], which would not have allowed the desired UHPLC analysis characteristics. The Cortecs T3 chemistry was then chosen for the method development.

\subsection{Experimental Design}

The experimental design provided valid models only helpful in describing the retention times $\left(t_{R}\right)$ and peak width at half-height $\left(w_{1 / 2}\right)$ of all the analytes. All other parameters collected by the automatic recording of the data from the chromatograms (i.e., peak area, signal to noise ratio, tailing factor, absolute noise) were instead affected by an excessive variance resulting in models that could not be validated. However, from the data of $t_{R}$ and $\mathrm{w}_{1 / 2}$ for each analyte peak, a reconstructed chromatogram, shown in Figure 1, was computed, assuming that the peaks had a Gaussian shape with a mean value coincident with the $t_{R}$ and standard deviation equal to $\mathrm{w}_{1 / 2} / 2.355$.

The model chromatogram reconstructed allowed to study the separation conditions that best coped with selectivity and speed of analysis while maintaining a good peak shape and sensitivity.

The final composition chosen was $0.021 \%(v / v)$ of formic acid and $4 \mathrm{mM}$ of ammonium formate for the aqueous component $(\mathrm{Ph}=3.58)$ and $0.021 \%(v / v)$ of formic acid for the organic component. These mobile phases were used for the method performance evaluation.

\subsection{Chromatographic Conditions}

As shown in Figure 1, there is accordance between the theoretical and experimental chromatograms, without major peaks of overlapping clusters. The observed overlapping can be easily worked around by mass spectrometry. The only exception lies in the doxorubicin-epirubicin pair; since they are diastereoisomers, both the retention times and MS fragmentations are extremely similar, making it hard to obtain base-resolved peaks under these chromatographic conditions; however, the peaks still can be identified by the retention time. 


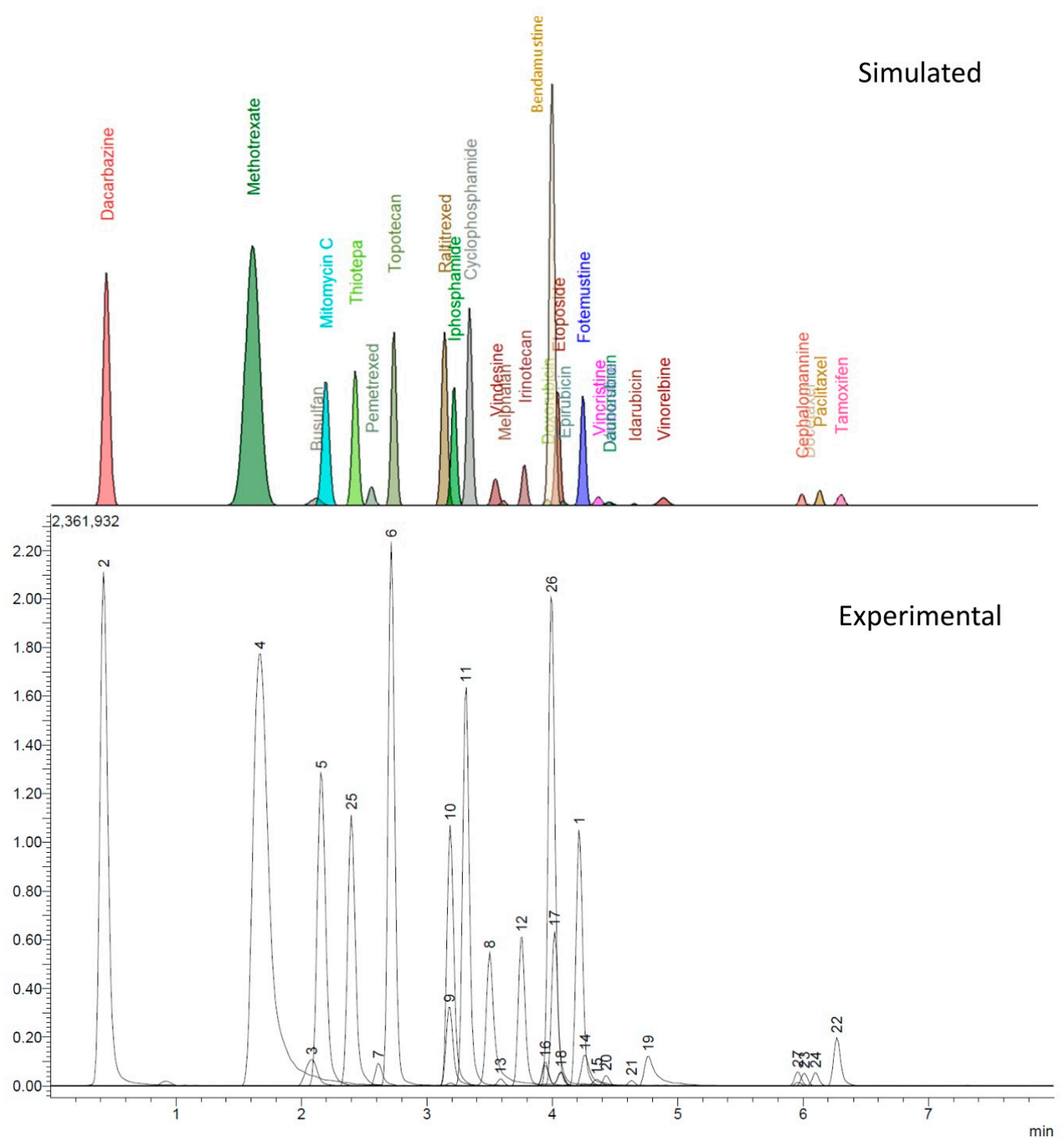

Figure 1. Comparing the accordance between computed and experimental chromatogram. LEGEND: 1, fotemustine; 2, dacarbazine; 3, busulfan; 4, methotrexate; 5, mitomycin C; 6, topotecan; 7, pemetrexed; 8, vindesine; 9, raltitrexed; 10, ifosfamide; 11, cyclophosphamide; 12, irinotecan; 13, melphalan; 14, vincristine; 15, vinblastine; 16, doxorubicin; 17 , etoposide; 18, epirubicin; 19, vinorelbine; 20, daunorubicin; 21, idarubicin; 22, tamoxifen; 23, docetaxel; 24, paclitaxel; 25, thiotepa; 26 , bendamustine; 27 , cephalomannine.

Table 4 reports values for retention time, peak width, tailing factor, asymmetry factor, theoretical plate number, and retention factor for each analyte, along with their relative standard deviation (RSD). The data can be used to build control charts to monitor column efficiency in routine applications. The retention factor values fall within the interval of $0.5<\mathrm{k}<20$ and were judged to be suitable for the goals of the separation based on the laboratory's internal expertise. 
Table 4. The analytes' retention times $\left(\mathrm{R}_{\mathrm{T}}\right)$, peak widths (Width $\left.\mathrm{H}_{1 / 2}\right)$, tailing factors $(5 \%)\left(\mathrm{T}_{\mathrm{f}}\right)$, asymmetry factors $(10 \%)\left(\mathrm{A}_{\mathrm{f}}\right)$, and their relative standard deviations (RSD), calculated plate numbers (N), and retention factors (k).

\begin{tabular}{|c|c|c|c|c|c|c|c|c|c|c|}
\hline \multicolumn{11}{|c|}{ Interday } \\
\hline Compound & $\mathbf{R}_{\mathrm{T}}(\min )$ & $\mathbf{R}_{\mathrm{T}} \mathbf{R S D}$ & Width $_{1 / 2}(\min )$ & Width RSD & $\mathbf{T}_{\mathbf{f}}$ & $\mathrm{T}_{\mathrm{f}} \mathbf{R S D}$ & $\mathbf{A}_{\mathbf{f}}$ & $\mathbf{A}_{\mathbf{f}} \mathbf{R S D}$ & $\mathbf{N}$ (plates) & $\mathbf{k}$ \\
\hline Fotemustine & 4.233 & $0.2 \%$ & 0.057 & $1.9 \%$ & 1.2 & $7.3 \%$ & 1.3 & $9.4 \%$ & 30,272 & 13.6 \\
\hline Dacarbazine & 0.426 & $0.5 \%$ & 0.067 & $2.6 \%$ & 1.3 & $4.6 \%$ & 1.4 & $6.0 \%$ & 227 & 0.5 \\
\hline Busulfan & 2.110 & $0.1 \%$ & 0.105 & $1.6 \%$ & 1.3 & $2.0 \%$ & 1.3 & $4.7 \%$ & 2252 & 6.3 \\
\hline Methotrexate & 1.751 & $0.6 \%$ & 0.125 & $1.4 \%$ & 1.5 & $5.0 \%$ & 1.6 & $9.4 \%$ & 1094 & 5.0 \\
\hline Mitomycin C & 2.198 & $0.3 \%$ & 0.071 & $1.8 \%$ & 1.3 & $4.8 \%$ & 1.3 & $6.9 \%$ & 5333 & 6.6 \\
\hline Topotecan & 2.737 & $0.2 \%$ & 0.057 & $1.9 \%$ & 1.2 & $6.1 \%$ & 1.3 & $7.9 \%$ & 12,731 & 8.4 \\
\hline Pemetrexed & 2.641 & $0.2 \%$ & 0.062 & $1.5 \%$ & 1.6 & $3.6 \%$ & 1.8 & $4.7 \%$ & 10,015 & 8.1 \\
\hline Vindesine & 3.522 & $0.2 \%$ & 0.067 & $3.4 \%$ & 1.7 & $3.6 \%$ & 1.8 & $5.3 \%$ & 15,183 & 11.1 \\
\hline Raltitrexed & 3.199 & $0.2 \%$ & 0.058 & $0.8 \%$ & 1.4 & $3.5 \%$ & 1.5 & $5.2 \%$ & 16,621 & 10.0 \\
\hline Ifosfamide & 3.209 & $0.2 \%$ & 0.059 & $2.3 \%$ & 1.3 & $7.2 \%$ & 1.3 & $9.6 \%$ & 16,169 & 10.1 \\
\hline Cyclophosphamide & 3.333 & $0.2 \%$ & 0.059 & $2.2 \%$ & 1.3 & $6.8 \%$ & 1.4 & $9.6 \%$ & 17,791 & 10.5 \\
\hline Irinotecan & 3.772 & $0.2 \%$ & 0.058 & $2.2 \%$ & 1.3 & $6.7 \%$ & 1.4 & $8.8 \%$ & 23,603 & 12.0 \\
\hline Melphalan & 3.609 & $0.2 \%$ & 0.058 & $2.2 \%$ & 1.3 & $5.9 \%$ & 1.3 & $8.2 \%$ & 21,621 & 11.4 \\
\hline Vincristine & 4.271 & $0.3 \%$ & 0.071 & $5.4 \%$ & 1.6 & $7.2 \%$ & 1.8 & $10.1 \%$ & 20,394 & 13.7 \\
\hline Vinblastine & 4.370 & $0.3 \%$ & 0.072 & $3.1 \%$ & 1.7 & $5.8 \%$ & 2.1 & $9.3 \%$ & 20,340 & 14.1 \\
\hline Doxorubicin & 3.963 & $0.3 \%$ & 0.057 & $2.3 \%$ & - & - & - & - & 26,623 & 12.7 \\
\hline Etoposide & 4.036 & $0.2 \%$ & 0.057 & $2.3 \%$ & 1.2 & $6.9 \%$ & 1.4 & $9.2 \%$ & 27,402 & 12.9 \\
\hline Epirubicin & 4.012 & $1.7 \%$ & 0.058 & $2.6 \%$ & - & - & - & - & 27,008 & 13.0 \\
\hline Vinorelbine & 4.787 & $0.2 \%$ & 0.081 & $3.8 \%$ & 2.4 & $7.6 \%$ & 2.9 & $5.7 \%$ & 19,214 & 15.5 \\
\hline Daunorubicin & 4.450 & $0.2 \%$ & 0.057 & $2.3 \%$ & 1.3 & $6.4 \%$ & 1.4 & $9.6 \%$ & 33,573 & 14.3 \\
\hline Idarubicin & 4.653 & $0.2 \%$ & 0.058 & $2.1 \%$ & 1.2 & $7.6 \%$ & 1.3 & $10.6 \%$ & 36,225 & 15.0 \\
\hline Tamoxifen & 6.278 & $0.2 \%$ & 0.062 & $2.1 \%$ & 1.3 & $3.7 \%$ & 1.4 & $4.5 \%$ & 56,300 & 20.6 \\
\hline Docetaxel & 6.025 & $0.2 \%$ & 0.057 & $2.5 \%$ & 1.1 & $4.9 \%$ & 1.2 & $8.5 \%$ & 62,404 & 19.8 \\
\hline Paclitaxel & 6.115 & $0.2 \%$ & 0.058 & $1.7 \%$ & 1.3 & $6.5 \%$ & 1.3 & $8.9 \%$ & 62,072 & 20.1 \\
\hline Thiotepa & 2.427 & $0.2 \%$ & 0.064 & $1.9 \%$ & 1.3 & $6.9 \%$ & 1.4 & $9.5 \%$ & 7974 & 7.4 \\
\hline Bendamustine & 4.013 & $0.2 \%$ & 0.058 & $1.9 \%$ & 1.3 & $6.2 \%$ & 1.4 & $8.6 \%$ & 26,434 & 12.8 \\
\hline IS & 5.974 & $0.2 \%$ & 0.058 & $2.0 \%$ & 1.2 & $8.1 \%$ & 1.4 & $11.5 \%$ & 59,268 & 19.6 \\
\hline \multicolumn{11}{|c|}{ Intraday } \\
\hline Fotemustine & 4.232 & $0.1 \%$ & 0.058 & $1.5 \%$ & 1.3 & $1.4 \%$ & 1.4 & $2.1 \%$ & 29,464 & 13.6 \\
\hline Dacarbazine & 0.425 & $0.2 \%$ & 0.068 & $1.0 \%$ & 1.3 & $1.1 \%$ & 1.5 & $1.2 \%$ & 217 & 0.5 \\
\hline Busulfan & 2.114 & $0.2 \%$ & 0.106 & $6.0 \%$ & 1.3 & $4.5 \%$ & 1.3 & $7.5 \%$ & 2200 & 6.3 \\
\hline Methotrexate & 1.761 & $0.3 \%$ & 0.126 & $1.4 \%$ & 1.6 & $1.7 \%$ & 1.8 & $2.8 \%$ & 1075 & 5.1 \\
\hline Mitomycin C & 2.200 & $0.1 \%$ & 0.072 & $1.2 \%$ & 1.3 & $1.2 \%$ & 1.4 & $1.9 \%$ & 5207 & 6.6 \\
\hline Topotecan & 2.736 & $0.1 \%$ & 0.058 & $2.0 \%$ & 1.3 & $1.9 \%$ & 1.4 & $2.3 \%$ & 12,337 & 8.4 \\
\hline Pemetrexed & 2.642 & $0.1 \%$ & 0.063 & $3.4 \%$ & 1.6 & $5.3 \%$ & 1.8 & $4.4 \%$ & 9886 & 8.1 \\
\hline Vindesine & 3.521 & $0.1 \%$ & 0.067 & $5.1 \%$ & 1.7 & $6.6 \%$ & 2.0 & $8.0 \%$ & 15,222 & 11.1 \\
\hline Raltitrexed & 3.199 & $0.1 \%$ & 0.059 & $2.0 \%$ & 1.4 & $1.5 \%$ & 1.5 & $3.1 \%$ & 16,377 & 10.0 \\
\hline Ifosfamide & 3.209 & $0.1 \%$ & 0.061 & $1.4 \%$ & 1.3 & $1.2 \%$ & 1.4 & $1.8 \%$ & 15,449 & 10.1 \\
\hline Cyclophosphamide & 3.333 & $0.1 \%$ & 0.060 & $1.6 \%$ & 1.3 & $1.2 \%$ & 1.4 & $2.1 \%$ & 17,063 & 10.5 \\
\hline Irinotecan & 3.770 & $0.1 \%$ & 0.059 & $2.1 \%$ & 1.3 & $1.6 \%$ & 1.5 & $3.3 \%$ & 22,729 & 12.0 \\
\hline Melphalan & 3.608 & $0.1 \%$ & 0.058 & $2.3 \%$ & 1.3 & $6.7 \%$ & 1.4 & $8.0 \%$ & 21,136 & 11.4 \\
\hline Vincristine & 4.268 & $0.1 \%$ & 0.070 & $3.6 \%$ & 1.6 & $12.0 \%$ & 1.9 & $11.6 \%$ & 20,761 & 13.7 \\
\hline Vinblastine & 4.369 & $0.1 \%$ & 0.073 & $9.7 \%$ & 1.8 & $18.6 \%$ & 2.2 & $16.4 \%$ & 19,973 & 14.1 \\
\hline Doxorubicin & 3.960 & $0.1 \%$ & 0.058 & $2.7 \%$ & - & - & - & - & 25,740 & 12.7 \\
\hline Etoposide & 4.035 & $0.1 \%$ & 0.058 & $1.7 \%$ & 1.3 & $1.6 \%$ & 1.4 & $2.6 \%$ & 26,389 & 12.9 \\
\hline Epirubicin & 3.962 & $0.4 \%$ & 0.058 & $2.4 \%$ & - & - & - & - & 26,096 & 12.7 \\
\hline Vinorelbine & 4.784 & $0.1 \%$ & 0.083 & $4.9 \%$ & 2.3 & $6.7 \%$ & 2.9 & $6.9 \%$ & 18,387 & 15.5 \\
\hline Daunorubicin & 4.447 & $0.1 \%$ & 0.058 & $3.3 \%$ & 1.3 & $5.7 \%$ & 1.5 & $7.1 \%$ & 32,322 & 14.3 \\
\hline Idarubicin & 4.650 & $0.1 \%$ & 0.058 & $4.1 \%$ & 1.3 & $8.4 \%$ & 1.5 & $11.9 \%$ & 35,238 & 15.0 \\
\hline Tamoxifen & 6.276 & $0.1 \%$ & 0.063 & $1.9 \%$ & 1.3 & $3.1 \%$ & 1.4 & $4.1 \%$ & 55,655 & 20.6 \\
\hline Docetaxel & 6.022 & $0.1 \%$ & 0.058 & $10.6 \%$ & 1.2 & $12.7 \%$ & 1.2 & $16.5 \%$ & 60,335 & 19.8 \\
\hline Paclitaxel & 6.111 & $0.1 \%$ & 0.059 & $2.8 \%$ & 1.3 & $4.7 \%$ & 1.4 & $6.7 \%$ & 60,199 & 20.1 \\
\hline Thiotepa & 2.429 & $0.1 \%$ & 0.065 & $1.7 \%$ & 1.4 & $2.0 \%$ & 1.5 & $2.8 \%$ & 7709 & 7.4 \\
\hline Bendamustine & 4.012 & $0.1 \%$ & 0.059 & $1.5 \%$ & 1.3 & $0.8 \%$ & 1.5 & $2.1 \%$ & 25,574 & 12.8 \\
\hline IS & 5.970 & $0.1 \%$ & 0.059 & $3.5 \%$ & 1.3 & $4.8 \%$ & 1.5 & $8.2 \%$ & 57,622 & 19.6 \\
\hline
\end{tabular}

\subsection{Mass Spectrometry}

The most abundant signal from each molecule cluster was chosen as the parent ion for the MS/MS analysis, avoiding, when possible, the sodium and potassium adduct ions. As shown in Table 3, the proton adduct ion $[\mathrm{M}+\mathrm{H}]^{+}$was found in most of the cases; exceptions were the Vinca alkaloids (vindesine, vincristine, vinblastine, vinorelbine) which presented a double charged $[\mathrm{M}+2 \mathrm{H}]^{2+}$ ion, busulfan, and etoposide, which adducted 
with ammonium ion $\left[\mathrm{M}+\mathrm{NH}_{4}\right]^{+}$and docetaxel, which could only be found as sodium adduct $[\mathrm{M}+\mathrm{Na}]^{+}$. Positive scan examples are reported in Supplementary Materials in Figures S1-S7.

Collision breakdown curves were created for each compound with the abundances obtained from PIS analysis and are reported in Figure S8 in Supplementary Materials. The analysis of these data allowed us to select the most suitable product ions and their optimal $\mathrm{CE}$ to set up the MRM methods. The monitored transitions have been chosen on the basis of higher abundance, lower noise level, and lack of interfering signals in the matrix.

\subsection{Method Performance Evaluation}

\subsubsection{Calibration Curves}

Drug products have been used instead of pure standards to create the calibration curves, even though the intrinsic imprecision was the actual concentration of the drug, which corresponds to the nominal value $\pm 5 \%$. This has been made to consider the possible variability in the analyte signals caused by the presence of excipients and thus obtain a more accurate view of real samples' responses. Table S1 reports the data obtained for linear regressions, $\mathrm{LOD}$, and $\mathrm{LOQ}$ for each analyte for the interday and intraday repetitions.

\subsubsection{Matrix Effect}

Table S2 in Supplementary Materials shows the results for ME experiments. As is shown, most of the analytes do not present a significant variation of the signal due to the matrix, exception made for vindesine, vinblastine, and docetaxel. This last compound shows a peculiar increase in the signal, which could be associated with an increased sodium cations concentration in the matrix.

\subsubsection{Accuracy and Precision}

Table S3 in Supplementary Materials reports accuracy and precision achieved for the three CQI levels during the performance evaluation. The overall precision and accuracy only show margins of error exceeding $15 \%$ for the compounds vindesine and docetaxel. The results obtained for docetaxel could be ascribed to the selection of its sodium adduct as precursor ion, which is usually avoided when possible. However, these results were considered acceptable for the laboratory's goals.

\subsection{Real Sample Analysis}

The method was applied to analyze some real samples during a campaign for monitoring ADs' surface contamination in a hospital administration unit.

From a panel of 72 samples, 16 end-shift wipes showed contamination of the daily used drugs, nine of which were greater than $100 \mathrm{pg} / \mathrm{cm}^{2}$, while 15 wipes sampled before the working shift had residual contamination of drugs utilized in the previous days, six of which greater than $100 \mathrm{pg} / \mathrm{cm}^{2}$.

\section{Discussion}

At the time being, biological monitoring for $\mathrm{AD}$ exposition presents too many issues, including the need to detect too low urinary levels and to use different extraction methods for each class of analytes, which would entail a complex and time-consuming procedure [11,12]. Surface monitoring results as a more versatile practice, allowing one to work on the correct application of the handling procedures and create a safer environment by focusing on prevention. The achievement of a fast screening method capable of detecting very low concentrations can lead to a better understanding of the contamination causes and spreading paths, helping to avoid future issues. In this scenario, the priority of the method development lies in the speed of analysis and the more comprehensive possible range of monitored compounds. The best choice for such an analysis lies in the desorption of wipes through a 50:50 water:methanol mixture and the subsequent analysis through LC-MS systems. The composition of the DS mixture has not been changed from previous 
studies [39] to maintain the same sample preparation and be able to test each solution through different analytical methods, and thus cover a more comprehensive range of ADs.

After confirming the stationary phase chemistry, the length choice fell on a shorter column than the one proposed by Guichard et al. [22]. Although this choice provided a lower resolution, it allowed instead to reduce by half the time of analysis, which is an essential result, considering that a single sampling campaign can consist of more than 200 wipes. Through a UHPLC system, the selected column led to the development of a 7 min gradient elution, with a total time of analysis of $13.2 \mathrm{~min}$. Compared to previous works [18,22], the panel of examined ADs has been increased, obtaining slightly lower LOQs and reducing significantly the time requested for the analysis.

The DoE approach has been a critical factor in the mobile phase optimization, minimizing the number of experiments and giving an intuitive response that allowed the selection of the most performing conditions. As shown in Figure 1, the predicted chromatogram for the selected conditions fits perfectly with the one obtained experimentally for what concerns the retention times and peak widths.

The method performance evaluation showed good repeatability for the chromatographic results of both the interday and intraday repetitions, with an overall error on precision and accuracy lower than $15 \%$, with the only exceptions lying in vindesine and docetaxel. For vindesine, the cause might be found in its asymmetric peak shape and greater base noise, while for docetaxel the issue could be ascribed to the lack of repeatability of the sodium adduct selected as precursor ion. The data obtained from linear regressions highlight that each analyte can be quantified at concentrations levels of $\mathrm{pg} / \mathrm{mL}$, with the only exceptions of vindesine and docetaxel that have LOQ values at the level of $10 \mathrm{ng} / \mathrm{mL}$.

The PQRI column comparison approach resulted as a fast way to determine whether or not valid alternatives to a selected column are present on the market.

Regarding the analyzed samples, the method succeeded in detecting both the contaminations due to the daily administrations and to the possible persistence of the drugs after cleaning procedures.

\section{Conclusions}

A high-throughput procedure based on a UHPLC-MS/MS analytical method to assess, qualitatively and quantitatively, $26 \mathrm{AD}$ surface potential contaminants has been proposed in the present study. First, the evaluation of studies reported in the literature and using the PQRI database allowed choosing the Cortecs UPLC T3 core-shell with trifunctional C18 alkyl stationary phase. This column could separate a wide variety of analytes in terms of different polarities and chemical structures. Subsequently, a simulation model was utilized to develop the chromatographic method, optimizing the separation between analytes and reducing the number of experiments requested in the development process. The obtained results showed adequate precision and accuracy with the possibility of quantifying $26 \mathrm{ADs}$ at the $\mathrm{pg} / \mathrm{mL}$ level, apart from few exceptions at the $\mathrm{ng} / \mathrm{mL}$ level. In conclusion, the UHPLC-MS/MS method presented can be applied to monitor AD surface contamination through a fast analysis and easy sample preparation.

Supplementary Materials: The following are available online at https://www.mdpi.com/article/10 .3390 / separations8090150/s1, Figure S1. Busulfan mass spectrum obtained by scan mode, Figure S2. Etoposide mass spectrum obtained by scan mode, Figure S3. Methotrexate mass spectrum obtained by scan mode, Figure S4. Vinblastine mass spectrum obtained by scan mode, Figure S5. Vincristine mass spectrum obtained by scan mode, Figure S6. Vindesine mass spectrum obtained by scan mode, Figure S7. Vinorelbine mass spectrum obtained by scan mode, Figure S8. Collision breakdown curves obtained from PIS analysis reporting collision energy CE (V) versus percentage abundance. The listed values reported in each spectra legend are respectively precursor and product ions, Table S1. Linear regression data, $\mathrm{R}^{2}$, LOD, and LOQ of each analyte, Table S2. Matrix effect values computed for each analyte, Table S3. Precision and accuracy values computed for the three quality control levels. 
Author Contributions: Conceptualization, S.D., D.S. and E.B.; methodology and validation, D.S., E.B., G.C. and L.T.; formal analysis, G.M., G.B. and C.M.; investigation, G.C.; resources, N.M. and L.T.; data curation, G.M., G.B. and C.M.; writing-original draft preparation, S.D., D.S. and E.B.; writingreview and editing, N.M. and G.A.; visualization, G.A.; supervision, G.A.; project administration, G.A. All authors have read and agreed to the published version of the manuscript.

Funding: This research received no external funding.

Institutional Review Board Statement: Not applicable.

Informed Consent Statement: Not applicable.

Data Availability Statement: Not applicable.

Conflicts of Interest: The authors declare no conflict of interest.

\section{References}

1. Sung, H.; Ferlay, J.; Siegel, R.L.; Laversanne, M.; Soerjomataram, I.; Jemal, A.; Bray, F. Global Cancer Statistics 2020: GLOBOCAN Estimates of Incidence and Mortality Worldwide for 36 Cancers in 185 Countries. CA Cancer J. Clin. 2021, 71, 209-249. [CrossRef] [PubMed]

2. Chauchat, L.; Tanguay, C.; Caron, N.J.; Gagné, S.; Labrèche, F.; Bussières, J.F. Surface contamination with ten antineoplastic drugs in 83 Canadian centers. J. Oncol. Pharm. Pract. 2019, 25, 1089-1098. [CrossRef] [PubMed]

3. Agents Classified by the IARC Monographs; Volumes 1-129. Available online: https://monographs.iarc.who.int/list-ofclassifications (accessed on 25 August 2021).

4. Guidance on the Application of the CLP Criteria, Guidance to Regulation (EC) No 1272/2008 on Classification, Labelling and Packaging (CLP) of Substances and Mixtures. July 2017. Available online: https:/ / echa.europa.eu/documents/10162/23036412 / clp_en.pdf/58b5dc6d-ac2a-4910-9702-e9e1f5051cc5 (accessed on 25 August 2021). [CrossRef]

5. Connor, T.H.; MacKenzie, B.A.; DeBord, D.G.; Trout, D.B.; O'Callaghan, J.P. National Institute for Occupational Safety and Health List of Antineoplastic and Other Hazardous Drugs in Healthcare Settings; US Department of Health and Human Services, Centers for Disease Control and Prevention; National Institute for Occupational Safety and Health: Cincinnati, OH, USA, 2016.

6. Directive 2004/37/EC of the European Parliament and of the Council of 29 April 2004 on the Protection of Workers from the Risks Related to Exposure to Carcinogens or Mutagens at Work (Sixth Individual Directive within the Meaning of Article 16(1) of Council Directive 89/391/EEC). 2004. Available online: https:/ / eur-lex.europa.eu/LexUriServ /LexUriServ.do?uri=OJ:L:2004: 229:0023:0034:EN:PDF (accessed on 25 July 2021).

7. European BioSafety Network. Preventing Occupational Exposure to Cytotoxic and Other Hazardous Drugs European Policy Recommendations. 2016. Available online: https://www.europeanbiosafetynetwork.eu/wp-content/uploads/2016/05/Exposureto-Cytotoxic-Drugs_Recommendation_DINA4_10-03-16.pdf (accessed on 25 July 2021).

8. European BioSafety Network. 2019 Amendments to the Carcinogens and Mutagens Directive (CMD). Available online: https: / / www.europeanbiosafetynetwork.eu/wp-content/uploads/2019/03/Amendments-to-CMD3-and-implications.pdf (accessed on 25 July 2021).

9. Lombardi, R.; Amari, P.; De Plato, F.; Falvo, C.; Jannitti, N.; Piredda, A. Gestione del Rischio di Esposizione del Personale Sanitario nella Manipolazione dei Farmaci Antineoplastici Iniettabili: Gli Aspetti di Prevenzione e la Caratterizzazione delle Misure di Sicurezza, Documento Italiano di Consenso. 2017. Available online: https://www.sifoweb.it/images/pdf/attivita/attivitascientifica/aree_scientifiche/area_oncologica/CONSENSUS_DOCUMENT_FINALE.pdf (accessed on 25 July 2021).

10. Yoshida, J.; Genshin, T.; Chie, M.; Yoshie, M.; Shigeki, K.; Shinji, K. Use of a Closed System Device to Reduce Occupational Contamination and Exposure to Antineoplastic Drugs in the Hospital Work Environment. Ann. Occup. Hyg. 2009, 53, 153-160. [CrossRef] [PubMed]

11. Dugheri, S.; Bonari, A.; Pompilio, I.; Boccalon, P.; Tognoni, D.; Cecchi, M.; Ughi, M.; Mucci, N.; Arcangeli, G. Analytical strategies for assessing occupational exposure to antineoplastic drugs in healthcare workplaces. Med. Pr. 2018, 69, 589-604. [CrossRef] [PubMed]

12. Palamini, M.; Dufour, A.; Therrien, R.; Delisle, J.-F.; Mercier, G.; Gagne, S.; Caron, N.; Bussieres, J.-F. Quantification of healthcare workers' exposure to cyclophosphamide, ifosfamide, methotrexate, and 5-fluorouracil by 24-h urine assay: A descriptive pilot study. J. Oncol. Pharm. Pract. 2020, 26, 1864-1870. [CrossRef] [PubMed]

13. Villa, A.; Molimard, M.; Sakr, D.; Lassalle, R.; Bignon, E.; Martinez, B.; Rouyer, M.; Mathoulin-Pelissier, S.; Baldi, I.; Verdun-Esquer, C.; et al. Nurses' internal contamination by antineoplastic drugs in hospital centers: A cross-sectional descriptive study. Int. Arch. Occup. Environ. Health 2021, 1-12. [CrossRef]

14. Dugheri, S.; Bonari, A.; Pompilio, I.; Gentili, M.; Montalti, M.; Mucci, N.; Arcangeli, G. A new automated gas chromatography/solid phase microextraction procedure for determining $\alpha$-fluoro- $\beta$-alanine in urine. Malays. J. Anal. Sci. 2017, 21, 1091-1100. [CrossRef]

15. Kibby, T. A review of surface wipe sampling compared to biologic monitoring for occupational exposure to antineoplastic drugs. J. Occup. Environ. Hyg. 2017, 14, 159-174. [CrossRef] 
16. Viegas, S.; Pádua, M.; Veiga, A.C.; Carolino, E.; Gomes, M. Antineoplastic drugs contamination of workplace surfaces in two Portuguese hospitals. Environ. Monit. Assess. 2014, 186, 7807-7818. [CrossRef]

17. Jeronimo, M.; Colombo, M.; Astrakianakis, G.; Hon, C.-H. A surface wipe sampling and LC-MS/MS method for the simultaneous detection of six antineoplastic drugs commonly handled by healthcare workers. Anal. Bioanal. Chem. 2015, 407, 7083-7092. [CrossRef]

18. Dugheri, S.; Bonari, A.; Pompilio, I.; Boccalon, P.; Mucci, N.; Arcangeli, G. A new approach to assessing occupational exposure to antineoplastic drugs in hospital environments. Arh. Hig. Rada Toksikol. 2018, 69, 226-237. [CrossRef]

19. Lee Walton, A.M.; Bush, M.A.; Douglas, C.E.; Allen, D.H.; Polovich, M.; Spasojevic, I. Surface Contamination With Antineoplastic Drugs on Two Inpatient Oncology Units. Oncol. Nurs. Soc. Forum 2020, 47, 263-273. [CrossRef]

20. Chabut, C.; Bussières, J.-F. Characteristics of wipe sampling methods for antineoplastic drugs in North America: Comparison of six providers. Pharm. Technol. Hosp. Pharm. 2020, 5. [CrossRef]

21. Mucci, N.; Dugheri, S.; Farioli, A.; Garzaro, G.; Rapisarda, V.; Campagna, M.; Bonari, A.; Arcangeli, G. Occupational exposure to antineoplastic drugs in hospital environments: Potential risk associated with contact with cyclophosphamide- and ifosfamide contaminated surfaces. Med. Pract. 2020, 71, 519-529. [CrossRef]

22. Guichard, N.; Feketea, S.; Guillarmea, D.; Bonnabrya, P.; Fleury-Souverainb, S. Computer-assisted UHPLC-MS method development and optimization for the determination of 24 antineoplastic drugs used in hospital pharmacy. J. Pharm. Biomed. Anal. 2019, 164, 395-401. [CrossRef]

23. Waters Expands CORTECS Analytical Column Portfolio. Available online: https://www.businesswire.com/news/home/201611 10005272/en/Waters-Expands-CORTECS-Analytical-Column-Portfolio (accessed on 25 July 2021).

24. Waters Launches New Cortecs T3 and Cortecs Shield RP18 Columns. 2016. Available online: https:/ /www.zenopa.com/news / 801828550/waters-launches-new-cortecs-t3-and-cortecs-shield-rp18-columns (accessed on 25 July 2021).

25. Berthelette, K.D.; Swann, T. Increased Retention of Polar Analytes Using CORTECS T3 Columns. Available online: https: //www.waters.com/webassets/cms/library/docs/720005946en.pdf (accessed on 6 July 2021).

26. Marrubini, G.; Dugheri, S.; Cappelli, G.; Arcangeli, G.; Mucci, N.; Appelblad, P.; Melzi, C.; Speltini, A. Experimental designs for solid-phase microextraction method development in bioanalysis: A review. Anal. Chim. Acta 2020, 1119, 77-100. [CrossRef] [PubMed]

27. Column Selector. Available online: https://www.acdlabs.com/resources/freeware/colsel/ (accessed on 25 July 2021).

28. USP Column Equivalency Application. Available online: https://apps.usp.org/app/USPNF/columnsDB.html (accessed on 25 July 2021).

29. USP Database. Available online: https://apps.usp.org/app/USPNF/columnsDB.html (accessed on 25 July 2021).

30. Haghedooren, E.; Diana, J.; Noszál, B.; Hoogmartens, J.; Adams, E. Classification of reversed-phase columns based on their selectivity towards vancomycin compounds. Talanta 2007, 71, 31-37. [CrossRef] [PubMed]

31. Visky, D.; Heyden, Y.V.; Iványi, T.; Baten, P.; De Beer, J.; Kovács, Z.; Noszál, B.; Roets, E.; Massart, D.L.; Hoogmartens, J. Characterisation of reversed-phase liquid chromatographic columns by chromatographic tests. Evaluation of 36 test parameters: Repeatability, reproducibility and correlation. J. Chromat. A 2002, 977, 39-58. [CrossRef]

32. Iványi, T.; Heyden, Y.V.; Visky, D.; Baten, P.; De Beer, J.; Lázár, I.; Massart, D.L.; Roets, E.; Hoogmartens, J. Minimal number of chromatographic test parameters for the characterization of reversed-phase liquid chromatographic stationary phases. J. Chromat. A 2002, 954, 99-114. [CrossRef]

33. Visky, D.; Heyden, Y.V.; Iványi, T.; Baten, P.; De Beer, J.; Kovács, Z.; Noszál, B.; Dehouck, P.; Roets, E.; Massart, D.L.; et al. Characterisation of reversed-phase liquid chromatographic columns by chromatographic tests: Rational column classification by a minimal number of column test parameters. J. Chromat. A 2003, 1012, 11-29. [CrossRef]

34. Matuszewski, B.K.; Constanzer, M.L.; Chavez-Eng, C.M. Strategies for the assessment of matrix effect in quantitative bioanalytical methods based on HPLC-MS/MS. Anal. Chem. 2003, 75, 3019-3030. [CrossRef] [PubMed]

35. PQRI Approach for Selecting Columns of Equivalent Selectivity. Available online: https://www.usp.org/resources/pqriapproach-column-equiv-tool (accessed on 25 July 2021).

36. Validation of Analytical Procedures: Text and Methodology Q2(R1). Available online: https://database.ich.org/sites/default/ files /Q2\%28R1\%29\%20Guideline.pdf (accessed on 25 July 2021).

37. Ying, H.; Hui, X.; Yaxiong, L.; Jiaming, G.; Quanhong, Y. Column selection approach for related substances determination of progesterone by high-performance liquid chromatography. Chem. Biol. Drug Des. 2019, 93, $29-37$.

38. C30 Series. Available online: https://develosil.us/product-category/c30-series/ (accessed on 25 July 2021).

39. Dugheri, S.; Mucci, N.; Mini, E.; Squillaci, D.; Marrubini, G.; Bartolucci, G.; Bucaletti, E.; Cappelli, G.; Trevisani, L.; Arcangeli, G. Characterization and Separation of Platinum-Based Antineoplastic Drugs by Zwitterionic Hydrophilic Interaction Liquid Chromatography (HILIC)-Tandem Mass Spectrometry, and Its Application in Surface Wipe Sampling. Separations 2021, 8, 69. [CrossRef] 